\title{
Original
}

\section{Extracellular Nucleic Acids Secreted by Lactobacillus Regulate TLR9 Expression}

\author{
Chun-Liang Liu, Shu Wen, Yin-Hui Liu, Hua-Jun Li, Jing Xiao and Li Tang
}

Department of Microecology, Dalian Medical University, 9 West Lvshun Southern Road 116044 Dalian, China

(Accepted for publication, June 12, 2011)

\begin{abstract}
Objective: The study was designed to determine the immune mechanism of nucleic acid sequences present in the medium filtrate of lactobacillus DM8909 at exponential growth phase. The effect of extracellular nucleic acids on TLR9 on the expression of IL-6 was also investigated.

Methods: Three groups were formed as nucleic acid group, CpG-ODN group and control group. Extracellular nucleic acids were examined by TA cloning and sequencing technology. RT-PCR and ELISA were used to detect the expressions of TLR9 and NF-אBp65 in HT-29 cells and the presence of IL-6 in the medium.

Results: The nucleic acids detected in the medium filtrate of lactobacillus DM8909 at exponential growth phase were found to be RNAs. A total of 39 RNA sequences were identified as lactobacillus delbrueckii subsp. Bulgaricus with a size of 49 bp, 23S ribosomal RNA and another RNA with a size of 52 bp identified as lactobacillus rhamnosus, ATCC 53103, tRNA-Leu sequence. TLR9 expressions in CpG-ODN and nuclei acid groups were higher compared to the control group (TLR-9 values were 3.2386, 0.4984 and 0.1780 respectively). The same results were obtained for NF-אBp65 where the expressions in CpG-ODN and nucleic acid groups were higher than the control group (relative values were 1.6671, 0.6501 and 0.3094 respectively). Furthermore, IL-6 expressions in CpG-ODN and nucleic acid groups were significantly higher than the control group (P $<0.05$, (relative values were $23.6735 \pm 1.4515,20.2041 \pm 1.6820$ and $15.7143 \pm 0.7047$ respectively).

Conclusion: The extracellular nucleic acids in the medium of lactobacillus DM8909 are RNAs and they could elevate the level of IL-6 through the activation of NF- $\mathrm{KB}$ and TLR9 in vitro. These molecules have similar immune activity with CPG-ODN.
\end{abstract}

Key words: Lactobacillus, RNA, TLR9, CpG-ODN, NF-кBp65, IL-6

\section{Introduction}

Lactobacillus is present in a wide range in human gastrointestinal tract and vagina. They play important roles like maintaining intestinal and vaginal self-stabilization, promoting maturation of the immune system and improving the immunity of the hosts ${ }^{1,2)}$. Lactobacillus DM8909 was isolated in a healthy woman's vagina in 1989 by our research team. It is a lactobacillus delbrueckii, which has been used to treat bacterial vaginosis in China. In 1999, its clinical use was approved by the Chinese Ministry of Health ${ }^{3)}$. Lactobacilli DM8909 used in the treatment of bacterial vaginosis obtained a success rate of $87.1 \%(54 / 62)$ and an improvement rate of 91.9\% (57/62). However, its immune mechanism against infection is still unknown. Nucleic acids about 100 bp were found in the medium of lactobacillus DM8909 at exponential growth phase but the composition, properties,

Correspondence to:Dr.Li Tang,Institute of Microecology, Dalian Medical University, Dalian, 116044•CPR China. Tel.: +86-411-8611-0152; Fax: +86-411-8611-0152. E-mail: tangli1484@sina.com sequence and immunological activity are not very clear. A recent study revealed that that cytosine-phosphate-guanosine oligodeoxynucleotide (CpG-ODN), an extracellular nucleic acid

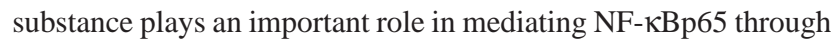
LTR9, in order to accommodate the cytokine and performs its role in the immune system ${ }^{4,5)}$. We explored the nucleic acid's immune mechanism via the effect of nucleic acids on LTR9mediated immune pathway.

\section{Materials and Methods \\ Bacterial strains and culture \\ Lactobacillus DM8909 was grown in the Department of Microecology, Dalian Medical University. Lactobacillus DM8909 was cultured in conventional LBS culture medium.}

\section{Extraction and identification of nucleic acids}

A total of $500 \mathrm{ml}$ of the medium where lactobacillus DM890 at exponential growth phase was collected and filtered by G6 
J.Hard Tissue Biology Vol. 20(2):153-160, 2011

Table 1. Primer synthesis and RT-PCR reaction conditions

\begin{tabular}{lccc}
\hline $\begin{array}{l}\text { Targeting } \\
\text { gene }\end{array}$ & Primer & $\begin{array}{c}\text { Fragments } \\
\text { length }\end{array}$ & $\begin{array}{c}\text { Annealing } \\
\text { temperature }\end{array}$ \\
\hline TLR9 & 5'-GCA CAG GAG CGG TGA AGG T-3’ & 820bp & $63^{\circ} \mathrm{C}$ \\
& 5'-GCA GGG GTG CTC AGT GGA G-3' & & \\
NF-êBp65 & 5'-ATG TGC ATC GGC AAG TGG -3' & 332bp & \multirow{2}{*}{$61^{\circ} \mathrm{C}$} \\
& 5'-TGC TGG GAA GGT GTA GGG -3' & & \\
â-actin & 5'-TCT ACG AGG GCT ATG CTC TCC-3' & 320bp & \multirow{2}{*}{$58^{\circ} \mathrm{C}$} \\
& 5'-GGA TGC CAC AGG ATT CCA TAC-3' & & \\
\hline
\end{tabular}

bacteria filter. An equal volume of pre-cooled ethanol was added into this filtrate. After shaking, the filtrate was centrifuged at $12,000 \mathrm{rpm}$ at $4^{\circ} \mathrm{C}$ for $20 \mathrm{~min}$. The precipitate was dissolved with DEPC water and $0.2 \%$ chloroform was added and thoroughly mixed.

Samples were set it in the ice box for $5 \mathrm{~min}$, centrifuged at 12,000 rpm at $4{ }^{\circ} \mathrm{C}$ for $15 \mathrm{~min}$ and the supernatant was collected. A volume of $0.6 \%$ isopropanol was added into the solution and was placed inside the ice box for $10 \mathrm{~min}$. The solution was then centrifuged at $12,000 \mathrm{rpm}$ at $4^{\circ} \mathrm{C}$ for $10 \mathrm{~min}$. The precipitate was collected and $75 \%$ ethanol was added and centrifuged at $7500 \mathrm{rpm} 4^{\circ} \mathrm{C}$ for 5 min. The sediment was washed with DEPC water and quantitative detection was done by UV spectrophotometer at A260. A solution of 10 ì solution was digested for 15 min with DNAase without RNAase and checked in $2 \%$ gel electrophoresis. Extracted RNAs were stored at $-80^{\circ} \mathrm{C}$ freezer, for sequence analysis and biological experiments.

\section{Sequence analysis of RNAs}

Sequence analysis of RNAs was performed at Shenzhen HuaDa Genetics Technology Co., Ltd. (www.genomics.cn). Briefly, 100 \pm 50 bp of RNA fragments by gel electrophoresis were purified and RNAs about 200-700 bp were made and connected by solexa joints to run the reverse transcription in the 3 ' and 5' end followed by PCR amplification. pMD18-T Vector kit was used to do TA cloning of PCR products. After cloning, BEST ${ }^{\mathrm{TM}}$ Sequencing Primers and M13 Primers were used to sequence the DNA (ABI3730 sequencing Instrument). Target sequences were separated by chrome software in peak sequencing and were analyzed one by one with Multalin multiple sequence alignment software online

(http://multalin.toulouse.inra.fr/multalin/multalin.html, http:// blast.ncbi.nlm.nih.gov/Blast.cgi, http://www.genomics.cn/ index.php).

RT-PCR analysis of the expression of TLR9 and NF-KBp65 in HT-29 cells
Cells were divided into three groups: nucleic acid group, CpGODN group and control group. Each group contains $300 \mu \mathrm{L}$ of HT-29 cells at a concentration of $1.0 \times 106 / \mathrm{mL}$. Nucleic acids and CpG-ODN were added to their respective group to reach a final concentration of $1.0 \mu \mathrm{M}$. Medium was added to the control group. The 3 groups were placed in incubator at $37^{\circ} \mathrm{C}$ with $5 \%$ $\mathrm{CO}_{2}$ for $48 \mathrm{~h}$. The cells were then collected, washed 3 times with cold PBS before total RNA extraction.

\section{Primer synthesis and RT-PCR detection}

The primers of the target genes NF-אBp65 and TLR9 were synthesized by Takara Biotechnology (Dalian) Co., Ltd. The primer volume for amplification of TLR9 and NF-кBp65 in nucleic acid group was $\mathrm{C} 2=1 \mu \mathrm{g} / \mu \mathrm{L}$, in CPG-ODN group was C3 $=1 \mu \mathrm{g} /$ $\mu \mathrm{L}$, in the control group was $\mathrm{C} 1=1 \mu \mathrm{g} / \mu \mathrm{L}$. The reaction conditions were as follows: pre-denaturing at $94^{\circ} \mathrm{C}$ for 2 min and annealing for $30 \mathrm{sec}$ with temperature determined by the primers designed (Table 1 ). When the reaction was completed, $5 \mathrm{~mL}$ reaction products were viewed at $1.5 \%$ agarose gel electrophoresis. The electrophoresis buffer was TAE with a voltage of $80 \mathrm{~V}$ for approximately $40 \mathrm{~min}$. The bands were analyzed by Quantity One electrophoresis gel imaging. Relative quantitative analysis of the bands was compared with $\beta$-actin to calculate the relative amounts of mRNA expression of TLR9 and NF- $\mathrm{kBp} 65$.

\section{IL-6 levels in HT-29 cell by ELISA}

HT-29 cells with a count of $1.0 \times 10^{6} / \mathrm{mL}$ each were divided into three groups. They were inoculated into 6 -well plates in duplicates and cultured at $37^{\circ} \mathrm{C}$ in $5 \% \mathrm{CO}_{2}$ incubation chamber. After confluence, nucleic acid and CpG-ODN were added into the corresponding wells to reach the final concentration of 1.0 $\mu \mathrm{M}$ and then cultured for $48 \mathrm{~h}$. Then after, the culture medium was collected, centrifuged at $2000 \mathrm{rpm}$ for $15 \mathrm{~min}$ and the supernatant was transferred into sterile EP tubes. Quantitative measurement of IL-6 was done with ELISA following the manufacturer's protocol. 
A

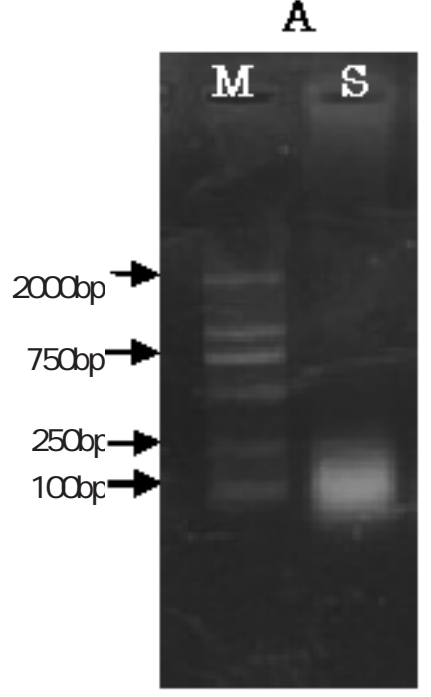

$\mathrm{B}$

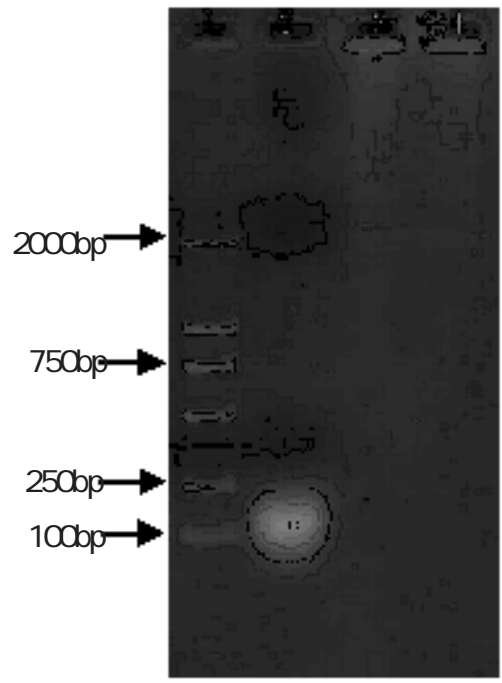

C

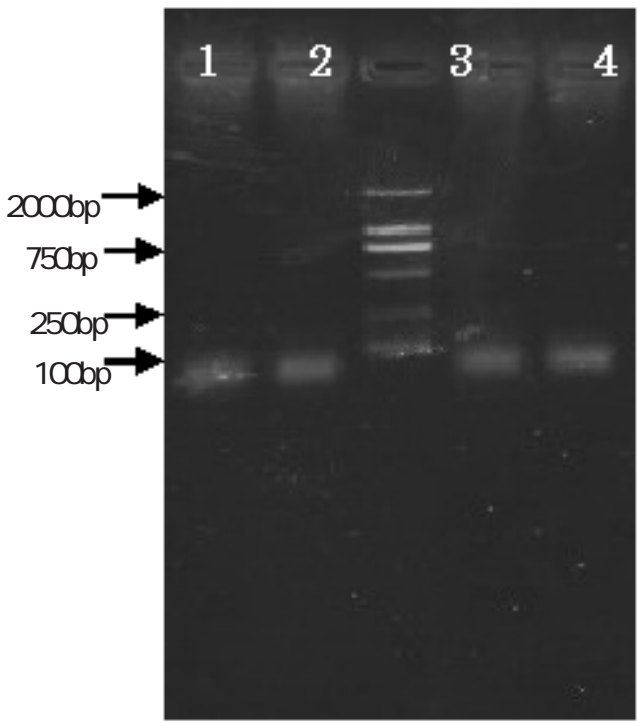

Figure1. The characteristics of the product extracted from the culture filtrate of lactobacillus DM8909 exponential growth phase. (A) The figure was performed by Takara Biotechnology (Dalian) Co., Ltd.. M: DNA Marker D2000, S: Sample. (B) The composition analysis of the product. Lane 1: DL2000 Marker, Lane 2: Sample, Lane 3: Sample-treated with RNase, Lane 4: Negative control (LBS not fermented). (C) The degradation of nucleic acids which was preserved in liquid nitrogen for approximately one month. Lane 1,2: New extracted nucleic acids, Lane 3: DNA Marker D2000, Lane 4,5: Nucleic acids preserved in liquid nitrogen for approximately one month.
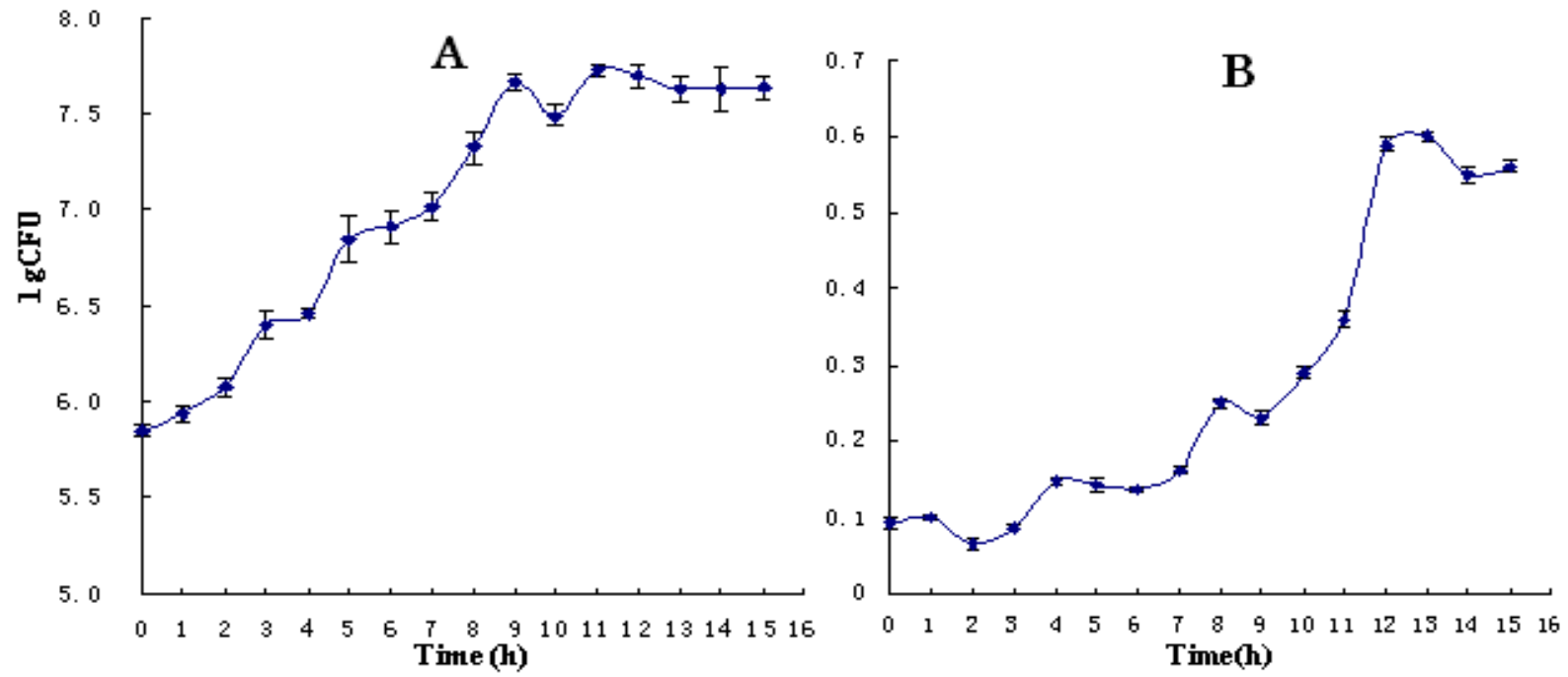

Figure 2. The growth curve of lactobacillus DM8909 (A) and the OD260 of the product extracted from its culture filtrate (B). Lactobacillus DM8909 was twice proliferated in LBS broth for 24h before inoculated into the detected system (large volume LBS broth). From Fig. 1 (A), the exponential growth phase of lactobacillus DM8909 was approximately 6 to $14 \mathrm{~h}$. According to the growth curve of lactobacillus DM8909, the OD260 value of the product extracted from the culture filtrate of lact

\section{Statistical analysis}

SPSS13.0 software was used for all computations. T-test was used as indicated by $\bar{x} \pm \mathrm{S}$. A P-value of $<0.05$ was considered significant.

\section{Results}

\section{Extraction and identification of nucleic acids}

Electrophoresis of the products from the culture filtrate of lactobacillus DM8909 at exponential growth phase revealed the existence of a large number of 100 bp nucleic acids (Fig. 1A). After the treatment of DNase (Free RNase), 50-100 bp RNAs were found (Fig. 1B). Excretion of RNAs at the exponential growth phase medium closely paralleled with the growth of bacterial counts showing a significant positive correlation (Fig. 2, Table 


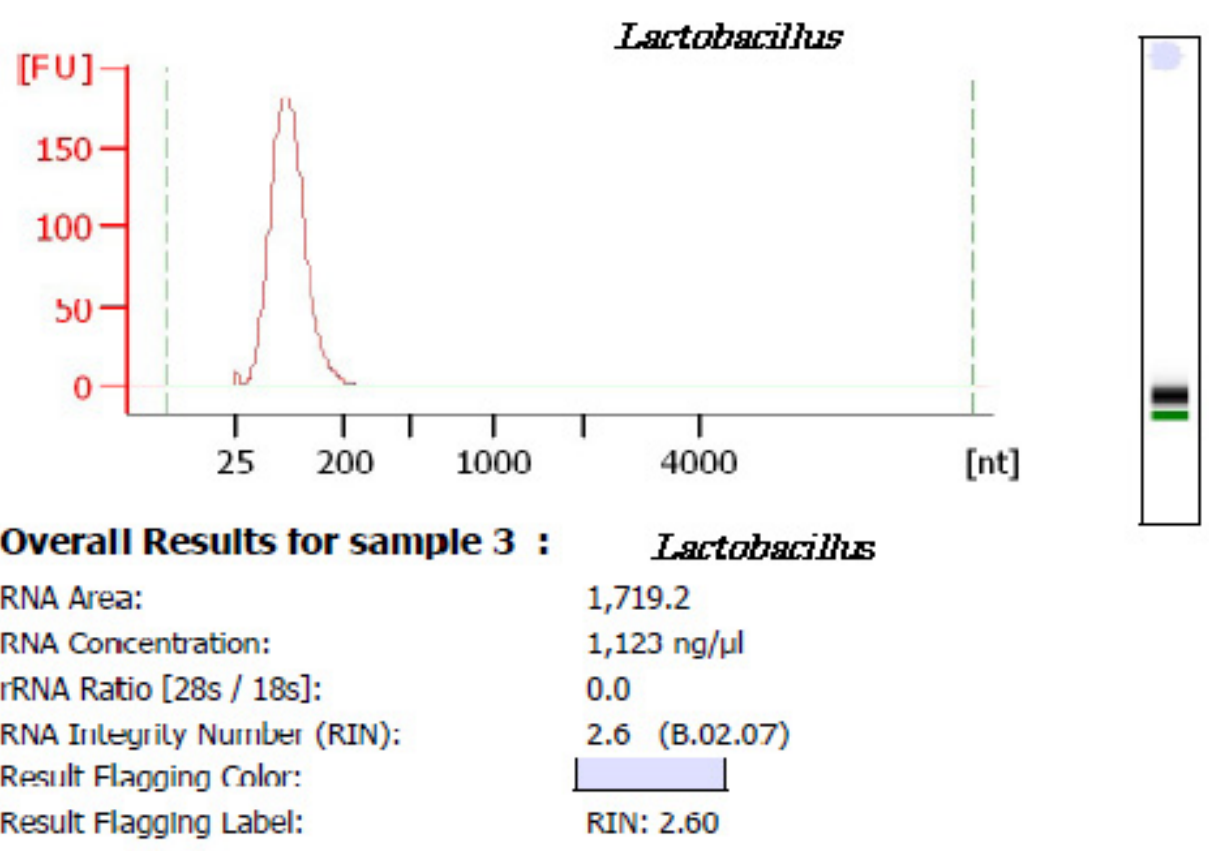

Fig 3. RNA abundance
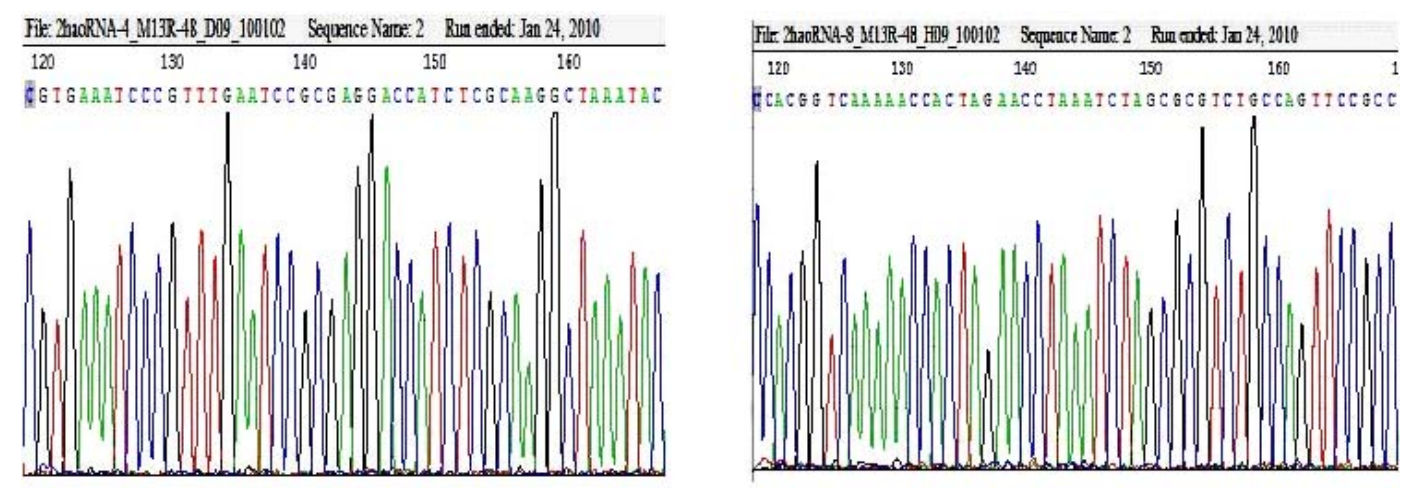

Fig.4 RNA sequencing map

Table 2.Solexa adapter sequences and PCR primers

\begin{tabular}{ll}
\hline & PE Adapter1.1 (32 bp) \\
Solexa adapter & 5' P- GATCGGAAGAGCGGTTCAGCAGGAATGCCGAG \\
sequences & PE Adapter2.1 (33 bp) \\
& 5'ACACTCTTCCCTACACGACGCTCTTCCGATCT \\
\hline & PE PCR Primer1.1 (58 bp) \\
& 5'AATGATACGGCGACCACCGAGATCTACACTCTTTCCCTACACGACGCTCTTCCGATCT \\
& PE PCR Primer2.1 (61 bp) \\
& 5'CAAGCAGAAGACGGCATACGAGATCGGTCTCGGCATTCCTGCTGAACCGCTCTTCCGATCT \\
\hline
\end{tabular}

2). The growth of lactobacilli reached a peak after $12 \mathrm{~h}$ at the exponential growth phase and the generation time of lactobacillus DM8909 is 1.95 h. Figure 3 shows RNA abundance.

\section{Sequence analysis of RNAs}

TA cloning of the medium filtrate of lactobacillus DM8909 at exponential growth phase obtained 39 RNAs sequences. Two of 
Chun-Liang Liu et al.: Bacterium Nucleic Acids Regulate Immunity

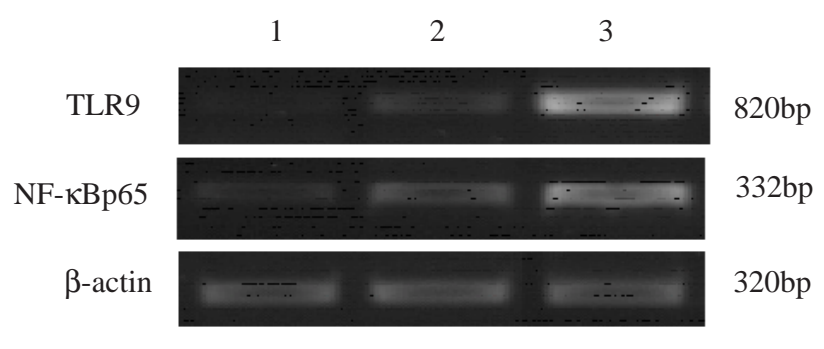

1- control group, 2- Nucleic acids group, 3- CpG-ODN group

Figure 5. Electrophoresis analysis the expression of TLR9, NF$\kappa B p 65$ in HT-29 cells teated with $n$ ucleic acids

them were absolutely clear, one was 49 bp with a sequence of CGTGAAATCCCGTTTGAATCCGCGAGGACCATCTCGCA AGGCTAAATAC identified as lactobacillus delbrueckii subsp. Bulgaricus. The other one is 23S ribosomal RNA and another was 52 bp with a sequence of CCACGGTCAAAAACCACTAGA ACCTAAATCTAGCGCGTCTGCCAGTTCCGCC identified as lactobacillus rhamnosus, ATCC 53103 tRNA -Leu (Fig. 4).

\section{RT-PCR analysis of the expression of TLR9 and NF-êBp65 in HT-29 cells}

Our research showed that the nucleic acids affected the expression of TLR9 and NF- $\mathrm{KBp} 65$ in HT-29 cells compared to the control group. TLR9 is higher in the nucleic acid group than the control group but lower than the CpG-ODN group (TLR-9 expression is 0.1780 in the control group, 0.4984 in the nucleic acid group and 3.2386 in CpG-ODN group). Likewise, NF-кBp65 expression is highest in CpG-ODN group followed by the nucleic acid and then the control group. (NF-KBp65 expression is 0.3094 in the control group, 0.6501 in nucleic acids group and 1.6671 in CpG-ODN group) (Fig. 5 and Fig. 6).

\section{IL-6 levels in HT-29 cells culture medium by ELISA}

The experiments showed that nucleic acids had an impact on the IL-6 levels in HT-29 cells compared to the control group. IL6 expression is significantly higher in the nucleic acid group

Table 3. IL-6 levels in the culture medium of HT-29 cells affected by nucleic acid components

\begin{tabular}{lcc}
\hline Group & N & IL-6 ug /g $(\bar{x} \pm S)$ \\
\hline Control group & 7 & $15.7143 \pm 0.7047^{\div \div}$ \\
Nucleic acid group & 7 & $20.2041 \pm 1.6820^{*} \div$ \\
CPG-ODN group & 7 & $23.6735 \pm 1.4515^{*}$ \\
\hline
\end{tabular}

Note: * $\mathrm{p}<0.05$ compared with the control group;

$3 \% \mathrm{p}<0.05$ compared with CPG-ODN intervention group group

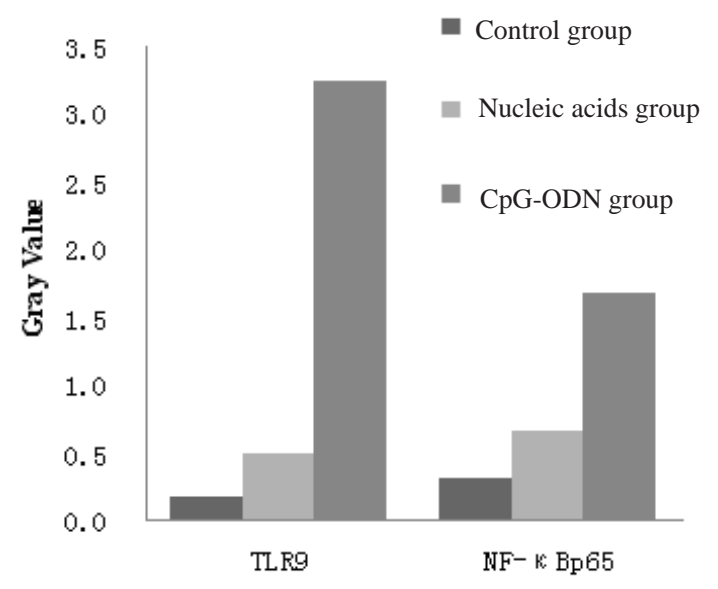

Figure 6. Relative value of TLR-9, NF-אBp65 in HT-29 cells treated with nucleic acids

secreted than in the control group but significantly lower than the CpG-ODN group (control group is15.7143 \pm 0.7047 , nucleic acid group is $20.2041 \pm 1.6820$, CpG-ODN group is $23.6735 \pm 1.4515$ ) (Fig. 7 and Table 3).

\section{Discussion}

There are over a thousand kinds of bacterial flora in the human intestine with total number of more than 1 trillion. They mainly establish colonies in the colon, forming a complex ecosystem with a wide range of bioactivity affecting the human's intestinal flora and normal functions. This phenomenon is closely related to the occurrence and development of intestinal diseases, particularly chronic infectious intestinal diseases ${ }^{6,7,8}$. Some metabolites of intestinal flora play an important role in this process, such as p40 and p75 proteins secreted by L.rhamnosus GG where in they could promote the growth and prevent tissue damage by excessive growth of TNF-á ${ }^{9}$. The metabolites which regulate the intestinal immune system and the function of immune cells directly are not very clear and little is known about the mechanism how metabolites influence the occurrence and development of chronic infectious intestinal diseases. TLRs are co-stimulatory receptors of foreign antigens which play an important role in identifying bacteria, regulating the immune responses induced by antimicrobial peptides and in removing pathogens. TLR9 expression on the apical and lateral intestinal epithelial basement membrane could identify the type of CpG-DNA molecules and then mediate host immune responses to bacterial cells. Experiments have confirmed that intestinal epithelial cells can either be in a "tolerated" or "non-tolerated" state in the intestinal flora depending on the signal transduction pathway which TLRs mediate ${ }^{10,11)}$.

\section{Some RNAs secreted by Lactobacillus are rRNA and tRNA}

Lactobacilli are important members of the human intestinal 
J.Hard Tissue Biology Vol. 20(2):153-160, 2011

flora. They are a kind of probiotics which are widely used in food and in the treatment of infectious diseases. Lactobacilli play an important role in the preventing infection via their metabolites such as volatile fatty acids, lactolin and unknown proteins they secrete. No other metabolic substance with this effect has been found according to our knowledge. Our research team found 39 RNA sequences in lactobacilli medium filtrate at exponential growth phase, including two certain lactobacillus' rRNA and tRNA sequences. Theoretically, the bacteria would not die in the exponential growth phase and no DNA was found in the filtrate. The phenomenon of RNA secretion was reported by DEMAIN AL in Bacillus subtilis in $1965^{18)}$ but have not been found in lactobacillus, so RNAs in the exponential growth phase culture filtrate maybe secreted by lactobacillus. rRNA which comprise $80 \%$ of total RNAs in the cell, play an important role in the process of protein synthesis. We have observed that non-protein-coding micro-RNAs regulate genes to resist virus in the cell recently ${ }^{12)}$, however, we know little about the role RNAs secreted by prokaryotic cells. Intestinal flora interacted with the body as an ecosystem or acting on the body through the cell itself or by metabolites such as secreted proteins. As a kind of biological macromolecules, rRNA and tRNA molecules have similar structure with DNA perhaps they have similar extracellular biological activity. Researches on extracellular RNA and DNA's role in cells are significant to describe the relationship between the intestinal flora and the body. Our research showed that as biological molecules, RNAs contact with the intestinal epithelial cells more easily and even could reach the lower intestinal epithelial cells. This may be it may the molecular mechanism behind the influence of intestinal flora in the stability of the immune system of the body.

\section{The immune activity of CpG-DNA}

Recent studies showed that CpG-ODN has a certain immune activity on the body. CpG-DNA molecules can induce the activation of several signal molecules by associating with TLR9 and then activating NF- $\kappa B$ at the same time blocking the activation of I $\mathrm{B}^{13,14)}$. In 1995, Krieg found that bacterial DNA can directly stimulate the proliferation of $\mathrm{B}$ cells and induce the secretion of IgM. They characterized by the structure of non-methylated cytosine guanine dinucleotide (CpG). This sequence appears in the genome of bacteria and viruses 20 times more than that of vertebrates ${ }^{15)}$. The binding of CPG-ODN and TLR9 induced the dimerization of TLR9 involved in signal transduction with the recruitment of myeloid differentiation factor 88 (MyD88). MyD88 plays a role by attracting IL-1 receptor associated kinase (IRAK) in inducing the degradation of $\mathrm{I} \kappa \mathrm{B}$ and activating $\mathrm{NF}-\kappa \mathrm{B}$ to regulate the synthesis and release of cytokines ${ }^{16)}$.

RNAs secreted by Lactobacillus can activate TLR9 and NF-кB

TLRs are evolutionarily conserved pattern recognition receptors expressed on the surface of a variety of immune cells. Intestinal epithelial cells recognize pathogens and other antigens to induce epithelial cells to produce cytokines, chemotatic factors, and anti-microbial peptides via TLRs. TLR9 exists in the basolateral and apical portion of the intestinal epithelial basement membrane in which TLR9 signaling pathways of IEC basolateral can activate NF- $\kappa \mathrm{B}^{17)}$. We studied the expression of TLR9 genes by RT-PCR and the experiments showed that RNAs secreted by lactobacillus can activate TLR9 compared to the control group. RNA increased by $180 \%$ while NF- $\mathrm{KB}$ increased by $110 \%$. The activity of CpG-ODN increased more significantly than RNAs that reached as high as $1719 \%$ and $439 \%$. RNAs in vitro culture filtrate at logarithmic growth phase of Lactobacillus activated TLR9 receptor to increase the activity of NF- $\kappa B$ suggesting that RNAs components secreted by Lactobacillus may be a new TLR9 ligand.

RNAs secreted by Lactobacillus can activate the secretion of IL6 by HT-29 cells

IL-6 is a cellular immune factor which can be expressed in a variety of body cells and is regulated by TLRs via NF- $\mathrm{KB}$ pathway which plays an important role in immunity ${ }^{18)}$. Our research detected IL-6 levels in the supernatant of RNAs group in HT-29 cells by ELISA. The results showed that nucleic acids secreted by lactobacillus could up-regulate IL-6 levels on HT-29 cells increasing by $28 \%$ compared to the control group, while the CpGODN group increased by $50 \%$. RNAs can promote the expression of IL-6 in vitro. Taken together, our data indicate that nucleic acids secreted by lactobacillus could promote the levels of IL-6 in vitro by activating TLR9 to generate NF- $\mathrm{BB}$ and that RNAs have similar immune activity with CpG-ODN.

\section{Conclusion}

The nucleic acids in lactobacillus DM8909 culture filtrate are RNAs which could increase IL-6 expression through the activation $\mathrm{NF}-\kappa \mathrm{B}$ via LTR9 mediation in vitro. It has a similar immune activity with the CpG-ODN.

\section{Acknowledgements}

This work was supported by grants from National Natural Science Foundation of China (30670054), National Program on Key Basic Research Project (973 Program, 2007CB513006).

\section{References}

1. Macpherson AJ, Gatto D, Sainsbury E, Harriman GR, Hengartner $\mathrm{H}$ and Zinkernagel RM. A primitive T cellindependent mechanism of intestinal mucosal IgA responses to commensal bacteria. Science 288:2222-2226, 2000

2. Mazmanian SK, Liu CH, Tzianabos AO and Kasper DL. An immunomodulatory molecule of symbiotic bacteria directs maturation of the host immune system. Cell 122(1):107-118,2005 
Chun-Liang Liu et al.: Bacterium Nucleic Acids Regulate Immunity

3. States Pharmacopoeia Editorial Board, ed by the third edition of Chinese Pharmacopoeia, Chinese Medical Science and Technology Publishing Inc. ,Beijing, 2010.

4. Cario E.Bacterial interactions with cells of the intestinal mucosa: Toll-like receptors and NOD2. Gut 54(8):11821193, 2005

5. Krieg M. A role for Toll in autoimmunity. Nat Immunol 3:423-425, 2002

6. Qin J, Li R, Raes J, Arumugam M, Burgdorf KS, Manichanh C, Nielsen T, Pons N, Levenez F, Yamada T, Mende DR, Li J, Xu J, Li S, Li D, Cao J, Wang B, Liang H, Zheng H, Xie Y, Tap J, Lepage P, Bertalan M, Batto JM, Hansen T, Le Paslier D, Linneberg A, Nielsen HB, Pelletier E, Renault P, Sicheritz-Ponten T, Turner K, Zhu H, Yu C, Li S, Jian M, Zhou Y, Li Y, Zhang X, Li S, Qin N, Yang H, Wang J, Brunak S, Doré J, Guarner F, Kristiansen K, Pedersen O, Parkhill J, Weissenbach J; MetaHIT Consortium, Bork P, Ehrlich SD and Wang J. A human gut microbial gene catalogue established by metagenomic sequencing. Nature 464(7285):59-65,2010

7. Hsieh SY, Tseng CL, Lee YS, Kuo AJ, Sun CF, Lin YH and Chen JK. Highly Efficient Classification and Identification of Human Pathogenic Bacteria by MALDI-TOF MS. Mol Cell Proteomics 7(2):448-456,2008

8. Ekbom A. The changing faces of Crohn's disease and ulcerative colitis, In:, Inflammatory Bowel Disease: From Bench to Bedside, ed by Targan S, Shanahan F and Karp LC, Kluwer Academic Publishers, Inc., Dordrecht, 2003, pp5 -20.

9. Sanchez B, Urdaci MC, Margolles A. Extracellular proteins secreted by probiotic bacteria as mediators of effects that promote mucosa-bacteria interactions. Microbiology 156: 3232-3242, 2010

10. Tlaskalová-Hogenová H, Stepánková R, Hudcovic T, Tucková L, Cukrowska B, Lodinová-Zádníková R,
Kozáková H, Rossmann P, Bártová J, Sokol D, Funda DP, Borovská D, Reháková Z, Sinkora J, Hofman J, Drastich P and Kokesová A.Commensal bacteria (normal microflora), mucosal immunity and chronic inflammatory and autoimmune diseases. Immunol Lett93(2-3): 97-108,2004

11. Ott SJ, Musfeldt M, Wenderoth DF, Hampe J, Brant O, Fölsch UR, Timmis KN and Schreiber S. Reduction in diversity of the colonic mucosa associated bacterial microflora in patients with active inflammatory bowel disease. Gut 53(5): 685-693, 2004

12. Demain AL, Burg RW and Hendlin D. Excretion and degradation of ribonucleic acid by bacillus subtilis. J Bacteriol 89: 640-646,1965

13. Weiler J, Hunziker J and Hall J. Anti-mRNA oligonucleotides (AMOs): ammunition to target miRNAs implicated in human disease. Gene Ther13(6): 496-502, 2006

14. Hemmi H, Kaisho T, Takeda K and Akira S. The roles of Toll-like receptor 9, MyD88, and DNA-dependent protein kinase catalytic subunit in the effects of two distinct CpG DNAs on dendritic cell subsets. J Immunol170(6): 30593064,2003

15. Akira $\mathrm{S}$ and Takeda K. Toll-like receptor signaling. Nat Rev Immunol4: 499-511, 2004

16. Chuang TH, Lee J, Kline L, Mathison JC and Ulevitch RJ. Toll-like receptor 9 mediates CpG-DNA signaling. J Leukocyte Biol71(3):538-544,2002

17. Pisetsky DS. Mechanisms of immune stimulation by bacterial DNA. Springer Semin Immunopathol22(12): 21-33, 2000

18. Leifer CA, Kennedy MN, Mazzoni A, Lee C, Kruhlak MJ and Segal DM. TLR9 is localized in the endoplasmic reticulum prior to stimulation. J Immunol173(2):1179-1183, 2004 
J.Hard Tissue Biology Vol. 20(2):153-160, 2011 